\section{As conjunções integrantes em dicionários escolares para o Ensino Médio}

Conjunctions in school dictionaries for high school

Ana Grayce Freitas de SOUSA (UECE) anagrayce@gmail.com

Recebido em: 26 de jul. de 2020. Aceito em: 24 de ago. de 2020.
SOUSA, Ana Grayce Freitas de. As

conjunções integrantes em dicionários

escolares para o Ensino Médio.

Entrepalavras, Fortaleza, v. 11,

n. esp., p. $64-80$, ago. 2021. DOI:

10.22168/2237-6321-10esp2005

Resumo: Os dicionários são obras que descrevem o léxico em suas mais variadas formas. Por isso, assim como a Gramática, um de seus papéis é a apresentação de informações sobre as palavras gramaticais, cujo sentido está diretamente relacionado a sua função sintática. Esse é o caso das conjunções, elementos gramaticais geralmente usados na conexão de outros elementos e fundamentais para a coesão textual. Partindo desse contexto, este artigo tem como objetivo descrever as informações lexicográficas presentes nos verbetes das conjunções integrantes que e se dos dicionários escolares tipo 4 presentes no PNLD-2012. Para compreender o conceito de conjunção, discutimos as ideias de pesquisadores como Cunha e Cintra (2017), Bechara (2009) e Bagno (2012), além dos trabalhos de Pontes (2009) e Brasil (2012), para entender como se organizam os dicionários escolares. Essa pesquisa tem orientação qualitativa e se propõe a ser descritiva em sua análise de dados. Nossos resultados apontam que a maioria dos verbetes analisados apresenta orientação gramatical nas informações lexicográficas sobre as conjunções integrantes, abordando sua função sintática, como ocorre 
comumente nas gramáticas. Podemos perceber, ainda, que a abordagem gramatical dada às conjunções pelas obras analisadas é de orientação normativa, pautada em regras e nomenclaturas, o que dificulta a compreensão dos verbetes para leitores que não conhecem as normas da sintaxe, especialmente as relacionadas à construção dos períodos compostos.

Palavras-chave: Lexicografia Pedagógica. Palavras Gramaticais. Paradigmas lexicográficos.

Abstract: Dictionaries are works that describe the lexicon in its most varied forms. Therefore, along with grammars, one of its roles is to present information about grammatical words, whose meaning is usually related to their syntactic function. This is the case of conjunctions. Understood as grammatical elements generally used to connect textual elements, they are fundamental for textual cohesion. Based on this context, this paper aims at describing the lexicographic information present in the entries of the subordinating conjunctions that and if in the type 4 school dictionaries of the Brazilian National Plan for the Didactic Books collection (2012 edition). In order to understand the concept of conjunction, we discuss the ideas of researchers such as Cunha and Cintra (2017), Bechara (2001) and Bagno (2012), in addition to the works of Pontes (2009) and Brazil (2012) to understand how school dictionaries are organized. As for the analysis of the data, this research has qualitative and descriptive orientation. Our results indicate that most of the entries analyzed have grammatical orientation in the lexicographic information they present about integral conjunctions, addressing their syntactic function, as commonly occurs in grammars. We could notice that the grammatical approach given to conjunctions in the works we have analyzed is oriented by standard language prescriptions, based on grammar rules and nomenclature, what hinders the comprehension of the entries for readers who do not know syntactic prescriptions, especially those related to compound sentences structure.

Keywords: Pedagogical Lexicography. Grammatical words. Lexicographic paradigms.

\section{Introdução}

As conjunções são palavras gramaticais responsáveis pela conexão de elementos textuais. Na grande maioria das vezes, estão relacionadas com a construção de períodos compostos, já que as coordenativas conectam orações coordenadas - independentes sintaticamente -, e as subordinativas introduzem uma oração subordinada. Além de atuarem na conexão de elementos e orações, as conjunções também auxiliam no estabelecimento de relações lógicosemânticas entre eles, visto que a classificação das orações coordenadas e subordinadas é influenciada pela conjunção presente entre as orações. Por exemplo, as orações coordenadas adversativas são ligadas por conjunções também classificadas como adversativas, como mas, porém.

As conjunções, nesse sentido, possuem um papel importante na compreensão e construção de textos, afinal, auxiliam no processo de construção de períodos compostos, presentes na estrutura textual. Ademais, são ainda elementos de extrema relevância na coesão textual, 
v. 11 (esp.)

$64-80$ ago. 2021

uma vez que atuam como conectores. Assim, o aprendizado dessas palavras gramaticais em sala de aula é de grande valor para a produção de textos, dos mais variados gêneros.

Esse aprendizado, vale ressaltar, pode ser facilitado pelo uso do dicionário, um instrumento linguístico que pode ser utilizado como material didático. Nele são esclarecidos inúmeros aspectos sobre o léxico, como significado, forma ortográfica, acentuação, tonicidade, contextos de uso etc. Essas obras lexicográficas podem ser excelentes ferramentas de auxílio à leitura e à produção de textos, se utilizadas de maneira eficiente por professores e alunos, como demostrado pelos estudos de Araújo (2005), Nascimento (2013), Sousa (2014). No caso das conjunções, em parceria com as gramáticas escolares, os dicionários podem ser apoio para a elucidação de diversas dúvidas sobre o conteúdo e o emprego dessa classe de palavras, usada, muitas vezes, de modo equivocado pelos alunos, como nos mostram as pesquisas de Grama (2016) e Sperança (2007).

Diante do exposto, este artigo tem como objetivo descrever as informações lexicográficas presentes nos verbetes das conjunções integrantes que e se dos dicionários escolares tipo 4 presentes no PNLD $^{1-2012 . ~ A ~ e s c o l h a ~ p e l a s ~ c o n j u n c ̧ o ̃ e s ~ i n t e g r a n t e s ~ d e v e-s e ~ a o ~ f a t o ~ d e ~}$ que esses elementos gramaticais estão presentes em diversas locuções conjuntivas, especialmente o que, o que torna relevante o seu estudo para uma melhor compreensão e emprego das demais conjunções.

Este artigo está organizado da seguinte forma: no próximo tópico, discutiremos as teorias que fundamentaram este estudo; em seguida, apresentaremos os materiais e métodos que tornaram possível este trabalho; depois, as análises dos verbetes selecionados; e, por último, nossas considerações finais.

\section{Referencial Teórico}

Para compreender melhor o conceito e as funções das conjunções, fundamentamos este trabalho nas discussões desenvolvidas no âmbito da Gramática, disciplina que tem como foco o estudo das estruturas que compõem a língua. Em relação às considerações sobre

${ }^{1}$ O PNLD - Programa Nacional do Livro Didático é uma política pública voltada para a avaliação, seleção e distribuição de material didático às escolas públicas do país. Desde 2001, vem incluindo em sua lista dicionários escolares, que são classificados em quatro tipos. Essa classificação tem como base no nível de proficiência linguística dos alunos de cada série escolar da educação básica. Os do tipo 4 são indicados para estudantes do ensino médio. 
os dicionários, nosso apoio teórico foi a Lexicografia, disciplina que tem como objeto de estudo obras lexicográficas. É válido ressaltar que, sendo os dicionários gêneros tão complexos, a Lexicografia apresenta vários campos de investigação. Em nossa pesquisa, utilizamos as teorias da Lexicografia voltadas para investigação de dicionários escolares, a Metalexicografia Pedagógica.

\section{As Conjunções integrantes}

As conjunções, assim como outras palavras gramaticais (artigos, preposições, pronomes e alguns advérbios), são de difícil definição, pois são mais reconhecidas pela função sintática que exercem do que pelo seu conteúdo. Assim, para compreendê-las, é preciso, muitas vezes, recorrer a conhecimentos gramaticais, especialmente os voltados para a construção de períodos compostos.

Para Cunha e Cintra (2017, p. 593), as conjunções são "os vocábulos gramaticais que servem para relacionar duas orações ou dois termos semelhantes da mesma oração". Os autores classificam as conjunções em dois tipos: a) as coordenativas - quando os elementos que a conjunção conecta apresentam relação de independência sintática; e b) as subordinativas - quando os elementos são dependentes sintaticamente.

Entre as conjunções subordinativas, estão elementos que introduzem orações subordinadas substantivas, as quais possuem funções desempenhadas por substantivos: sujeito, predicado, objeto direto, objeto indireto, complemento nominal, aposto e agente da passiva. São as chamadas conjunções integrantes, representadas por que e se.

Bechara (2009), em sua gramática, assim como Cunha e Cintra (2017,) aponta que e se como conjunções integrantes. No entanto, este autor faz uma ressalva em relação à função das conjunções subordinativas. Para ele, esse tipo de conjunção pode ser denominado de transpositor, porque, na subordinação, há a transformação de uma oração para o nível gramatical de uma palavra (substantivo, adjetivo ou advérbio), que está subordinada a uma oração principal. Quando uma oração passa a desempenhar o papel de um substantivo, ela recebe a classificação de oração subordinada substantiva; em advérbio, oração subordinada adverbial; em adjetivo, oração subordinada adjetiva. Assim, o transpositor não faz parte da oração dependente, como defendem gramáticas normativas, mas atua como um elemento de ligação e transposição. 
v. 11 (esp.) $64-80$ ago. 2021
Esse conceito gramatical assumido por Bechara (2009) também é defendido por Bagno (2012), que define que e se como nominalizadores. O autor mantém a classificação desses elementos como conjunções integrantes, mas assume que as locuções formadas por essas partículas e outras palavras como advérbios, verbos e pronomes não seriam conjunções, mas a junção de um nominalizador a uma palavra de outras classes gramaticais.

Essa visão de Bagno (2012), vale destacar, mudaria muitas das classificações que conhecemos hoje como locuções conjuncionais, o que poderia simplificar o aprendizado das conjunções, já que a maioria é formada por uma palavra (de outras classes gramaticais) e um transpositor (conjunção). As locuções conjuncionais seriam vistas, nesse sentido, como essa junção de classes de palavras, não mais como conjunções, o que poderia diminuir as dúvidas dos alunos em relação ao uso dessa classe de palavras tão heterogênea.

Através do estudo dos transpositores, também poderíamos compreender melhor a formação dos períodos compostos por subordinação, pois os limites entre as orações principais e as subordinadas seriam mais claros, demarcados pelas conjunções. Ademais, entender os processos de construção sintática e semântica desses períodos, sem ter como foco a classificação das orações ou das conjunções que os conectam (o que normalmente acontece no ensino de gramática na escola baseado em regras e nomenclaturas) poderia ser mais relevante para a produção de textos mais coerentes e coesos.

\section{Os Dicionários escolares}

Segundo Brasil (2012), os dicionários são livros que se propõem a fazer descrições, mais ou menos detalhadas, do léxico de uma língua. São o registro do léxico nas suas mais variadas faces: linguística, histórica, cultural, ideológica etc. Por isso, além de auxiliarem na compreensão das palavras de uma língua, essas obras lexicográficas fazem parte da construção identitária de um povo.

Ainda de acordo com Brasil (2012), os dicionários resultam de posicionamentos teóricos diversos sobre o léxico. Nesse sentido, podem apresentar estruturas bastante distintas, com objetivos e públicos diferentes. Assim, há vários tipos de dicionários: para aprendizes de línguas estrangeiras ou materna, para níveis de proficiência linguística avançada ou inicial, de orientação por ordem alfabética ou por campos 
semânticos, específicos para profissionais de uma determinada área técnica ou para o público geral. A tarefa de classificá-los é, portanto, complexa, visto existirem variados parâmetros para isso.

Um dos princípios para uma tipologia de dicionários é o nível de proficiência linguística dos usuários dessas obras, como nos aponta Pontes (2009). Entre os quatro tipos descritos pelo autor, há os direcionados para usuários que se encontram em período de aprendizagem da língua: o dicionário infantil e o dicionário escolar (língua materna).

São os dicionários escolares, foco desse trabalho, obras que possuem estruturas adequadas para um consulente que ainda está desenvolvendo suas habilidades de leitura e escrita. Por isso, são materiais didáticos que podem ser utilizados na escola, nas aulas de língua portuguesa e de outras disciplinas. Nesse sentido, o PNLD-2012 inclui em sua lista dicionários que são diferenciados pelas necessidades de aprendizagem dos alunos de cada etapa da educação básica. O programa, então, classifica as obras selecionadas em quatro tipos: dicionários tipo 1 - para crianças do $1^{\circ}$ ano do Ensino Fundamental; dicionários tipo 2 - para alunos do $2^{\circ}$ ao $5^{\circ}$ ano do Ensino Fundamental; dicionários tipo 3 - para alunos do $6^{\circ}$ ao $9^{\circ}$ ano do Ensino Fundamental; e os dicionários tipo $4^{-}$para alunos do $1^{\circ}$ ao $3^{\circ}$ ano do Ensino Médio.

Os dicionários direcionados para estudantes dos últimos anos da educação básica, objeto de análise deste trabalho, possuem "mínimo de 40.000 e máximo de 100.000 verbetes; e proposta lexicográfica própria de um dicionário padrão, porém adequada às demandas escolares do ensino médio, inclusive o profissionalizante (BRASIL, 2012, p. 19).

Como podemos notar, os dicionários tipo 4 são obras que possuem uma maior quantidade de verbetes e uma proposta lexicográfica voltada para o auxílio da leitura e da escrita de textos mais complexos, já que essa é a realidade de seus usuários, estudantes do Ensino Médio. Assim como o dicionário padrão, esses tipos possuem microestrutura ${ }^{2}$ mais extensa, com informações mais detalhadas sobre a unidade léxica definida.

De acordo com Pontes (2009, p. 95), a microestrutura é um "conjunto de paradigmas e estruturas dispostas horizontalmente, ou seja, linearmente, após a entrada, dentro de cada verbete". Os

\footnotetext{
${ }^{2}$ Segundo Pontes (2009), os dicionários são constituídos de quatro estruturas: macroestrutura/ megaestrutura, nomenclatura, microestrutura e medioestrutura. Dada a extensão desse trabalho, vamos nos concentrar nos elementos que integram a microestrutura, elemento analisado neste artigo.
} 
v. 11 (esp.) $64-80$ ago. 2021 paradigmas, vale ressaltar, são os elementos informativos sobre as entradas. Etimologia, informações fonéticas, definição são exemplos de paradigmas presentes em verbetes de dicionários escolares. Alguns paradigmas são quase obrigatórios, enquanto outros são facultativos, dependendo do objetivo e do público para o qual a obra lexicográfica é direcionada. Pontes (2009), nesse sentido, aponta que, geralmente, um dicionário escolar apresenta um programa de microestrutura com os seguintes paradigmas: definição, exemplo de uso, marcas de uso, remissivas.

Essas informações são agrupadas, segundo Barbosa (1990) citada por Pontes (2009) em três paradigmas:

a) Paradigma informacional: dados sobre a unidade léxica enquanto significante (categoria gramatical, gênero, número, conjugação, pronúncia, abreviações, homônimos);

b) Paradigma definicional: dados sobre a unidade léxica enquanto significado (definição);

c) Paradigma pragmático: dados sobre a unidade léxica relativos ao seu uso contextual (exemplos de uso, marcas de uso).

São esses paradigmas, adicionados à entrada, que formam o verbete, principal texto do dicionário.

Após a discussão de nossas bases teóricas, descrevemos a metodologia que tornou possível a realização deste trabalho.

\section{Metodologia}

Esta pesquisa tem natureza qualitativa e se classifica como do tipo descritiva, visto que nosso interesse está na observação e análise de um fenômeno, a descrição das conjunções integrantes em dicionários escolares para estudantes do ensino médio. Assim, nosso foco está no processo de compreensão das informações presentes nos textos analisados, não nos preocupando com quantificações, números ou estatísticas.

Nosso foco de análise são, portanto, as estruturas lexicográficas presentes nos verbetes e de que modo esses elementos constroem o conceito dessa classe de palavras tão relevante para a construção da coesão na produção de textos. Desse modo, analisaremos todos os elementos da microestrutura, ou seja, o paradigma informacional, o paradigma definicional e o paradigma pragmático (PONTES, 2009). 
Os dicionários analisados estão presentes no PNLD-2012, que inovou ao incluir em sua seleção e distribuição obras lexicográficas voltadas ao ensino médio, classificados pelo programa de tipo 4. São eles,

- Dicionário da língua portuguesa Evanildo Bechara (BECHARA, 2012);

- Dicionário Unesp do português contemporâneo (BORBA, 2011);

- Novíssimo Aulete dicionário contemporâneo da língua portuguesa (GEIGER, 2012); e

- Dicionário Houaiss conciso (HOUAISS, 2011)3.

Vale ressaltar que a escolha de obras lexicográficas presentes no PNLD-2012 deve-se à importância do programa para a Lexicografia brasileira, visto que, ao longo de seus vinte anos de existência, tem selecionado dicionários escolares tendo como um de seus critérios a adequação da obra à proficiência linguística do aluno em cada etapa da educação básica (SOUSA; SANTOS, 2020). Esse também é um dos princípios defendidos pela Lexicografia Pedagógica, que sugere a adequação do dicionário às necessidades de aprendizagem do usuário. Assim, obras direcionadas para estudantes do ensino médio terão estruturas diferentes daquelas voltadas para crianças em fase de alfabetização.

Nosso corpus de análise é composto por oito ocorrências referentes a 2 entradas (as conjunções que e se) extraídas dos quatro dicionários apresentados.

\section{Análise e discussão dos dados}

Para uma melhor organização das análises, optamos por apresentar os dois verbetes ${ }^{4}$ de cada dicionário, para em seguida tecer comentários sobre eles. É válido ressaltar que os verbetes são compostos por mais de uma acepção, visto que as entradas estudadas podem apresentar mais de um sentido; no entanto, nossas considerações serão voltadas, em sua maioria, às informações que categorizam a conjunção integrante. A seguir, estão os verbetes que e se do Bechara:

que $^{2}$ conj. integr. 1 Introduz oração subordinada subst. com função de sujeito ou complemento (objeto direto, objeto

\footnotetext{
3 Doravante, faremos referência aos dicionários como Bechara, Unesp, Aulete e Houaiss.

${ }^{4}$ Como o foco deste trabalho não são os aspectos visuais dos verbetes, eles foram copiados de modo simplificado, sem os símbolos e as diferenciações de cores e de tipologia usados pelos dicionários.
} 
v. 11 (esp.)

$64-80$ ago.

2021

indireto, complemento relativo, predicativo, complemento nominal ou aposto). P. ex., em 'É preciso que estudemos todos os dias', que estudemos todos os dias é o sujeito de É preciso. OBS.: 1) No português corrente, substitui: a) prep. de: Tenho que sair. b) prep. a: Prefiro ouvir que falar. 2) Por omissão de verbos como espero, desejo, etc., inicia frases de estímulo, invocação, etc.: Que vença o melhor! conj. comp. 2 introduz o segundo termo da comparação, antecedido ou não da prep. de. Era mais culto (do) que eles. conj. consec. 3 Introduz oração subordinada adverbial na qual se expressa o resultado o que foi dito na oração principal. Estou tão cansado que não vou comer. conj. expl. 4 Introduz oração subordinada adverbial na qual se expressa o motivo do que foi dito na oração principal; porque, devido a. Vá embora que você já me encheu. No que No exato momento em que; assim que. Que não A não ser; exceto. Que nem Assim como; tal qual. [Do lat. quia] (BECHARA, 2011, p. 971)

$\mathbf{s e}^{2}$ conj. condic. 1 No caso de; caso. Se não chover, viajaremos. conj. caus. 2 Já que, dado que. conj. integr. 3 Introduz uma oração subordinada integrante. Não disse se iria à solenidade. [Do lat. Si.] (BECHARA, 2011, p. 1035)

Vemos que o verbete que é constituído por quatro acepções, que definem cada uma das classificações dessa conjunção, que pode assumir o valor de conjunção integrante,conjunção adverbial comparativa, consecutiva e explicativa. A marcação da classe gramatical, presente no paradigma informacional, como podemos perceber, é bastante relevante, pois esse elemento assume uma função específica quando se trata se uma conjunção integrante, a de introduzir oração subordinada substantiva. Ainda nesse paradigma, observamos, ao final do verbete, a etimologia da entrada. Assim como o dicionário geral, o do tipo 4 apresenta o léxico de modo mais detalhado, por isso, é comum vermos dados sobre a origem de uma palavra.

No paradigma definicional, vemos que a definição, constituída por uma proposição, é baseada na função sintática que esse elemento exerce nos períodos compostos. Para definir que, o dicionário usa, nesse sentido, termos da gramática. Observamos que o paradigma pragmático, que informa sobre o emprego da palavra definida, é feito através de exemplos de uso, acompanhado de uma explicação, parecida com as vistas em gramáticas. Notamos que os exemplos são simples, de linguagem cotidiana, assim como acontece com as orientações de nível gramatical. Há ainda, dentro desse paradigma, observações sobre substituições comumente feitas com essa conjunção. Embora não seja o foco desse trabalho, é interessante notar que, no verbete acima, há a presença de subentradas, nesse caso, locuções. No entanto, diferente do que acontece com a entrada, a definição é construída a partir de 
sinônimos, sem orientações gramaticais, nem exemplos. Ao lermos as subentradas, há a dúvida sobre qual tipo de conjunção as locuções são e como elas podem ser empregadas.

Em comparação com o verbete que, o se é bem menos extenso e apresenta três acepções, uma para a classificação de conjunção condicional, outra para a conjunção causal, e a última para a conjunção integrante.

Em relação à identificação da classe gramatical, observamos que o se traz uma classificação um pouco diferente do que. No que, há menção à oração subordinada substantiva, já no se o termo escolhido foi oração subordinada integrante. Embora gramaticalmente sejam sinônimos, um aluno que não tenha esse conhecimento gramatical pode ficar confuso, visto que as gramáticas utilizam normalmente a classificação usada no que.

Com relação ao paradigma definicional, há novamente uma definição construída por uma proposição, de orientação gramatical. Observamos que, embora a conjunção como partícula condicional também exerça função de conectivo, as definições relativas a ela são sinonímicas, o que destoa da integrante. Aqui, o dicionário reforça a ideia de que o se como conjunção integrante não possui significado, mas apenas uma função sintática.

O paradigma pragmático é constituído, nesse caso, por um exemplo de uso, sem nenhuma explicação gramatical, como ocorreu com o verbete que. Há ainda, no final do verbete, uma informação sobre a origem etimológica do se, pertencente ao paradigma informacional.

Ao lermos os verbetes que e se, notamos que há um maior detalhamento das funções sintáticas e usos do que, o que faz com que as orientações pedagógicas auxiliem o aluno a compreender e utilizar essa partícula. No se, no entanto, parece que o consulente já deve ter vários conhecimentos prévios sobre a palavra pesquisada, já que a sua descrição é feita de modo mais enxuto e com termos da gramática.

Para prosseguirmos com nossas análises, abaixo, apresentamos os verbetes que e se do Unesp:

QUE ${ }_{2}$ conj [Subordinativa. Integrante] 1 introduz uma oração que funciona como sujeito ou como complemento da principal: É bom que vocêsaiba logo a verdade. A pesquisa revelou que a gordura de coco-babaçu controla a taxa de colesterol. [Comparativa] $\mathbf{2}$ introduz o segundo termo da comparação precedido ou não de de: Zina é mais magra do que Jane. Pedro estuda menos do que Luciano. [Consecutiva] [em relação com tão/tanto/tal/tamanho] 3 introduz uma oração que expressa o efeito ou a consequência 
v. 11 (esp.)

$64-80$

ago.

2021

daquilo que se apresenta na oração principal. Carlinho chorou tanto que até adormeceu. Estava tão cansado que dormiu ali mesmo, no sofá. As crianças fizeram tamanha algazarra que a professora precisou mandá-las sair da sala. [Concessiva] [+v. no subj.] 4 ainda que; embora: O engarrafamento era imenso, ninguém avançava um centímetro que fosse. [Temporal] $\mathbf{5}$ desde que: Faz duas semanas que cheguei de viagem. [Coordenativa. Aditiva] 6 e: Basta você dar um grito que eles vêm correndo. [Adversativa] $\mathbf{7}$ mas, senão: O autor da brincadeira não podia ser outro que não o Paulinho. [Explicativa] $\mathbf{8}$ apresenta a razão ou o motivo do que se constatou na oração anterior; porque: Não chora, que não estou aqui para ouvi lamúrias. Prep. [ter+ q] 9 de: Tínhamos que viajar até Limeira. Q. nem/só como: Dizem que ele morreu que nem um passarinho. Em frases interrogativas e exclamativas, a expressão ser+ que pode reduzir-se a que, no registro coloquial: Quem foi que disse isso? > Quem que disso isso? Quanto era que custava a bicicleta? > Quanto que custa a bicicleta? Como é que uma pessoa pode ser tão falsa! > Como que uma pessoa pode ser tão falsa! (BORBA, 2011, p. 1154)

$\mathbf{S E}_{\mathbf{2}}$ Conj. [Subordinativa. Condicional] $\mathbf{1}$ dada a circunstância de que; caso: Tudo seria diferente se vocês colaborassem um pouco mais. 2 caso: Se você dispuser de tempo, visite também o mercado municipal. Sabia que, se continuasse dessa forma, nada em sua vida duraria muito. 3 introduz a suposição de uma causa na correlação se... é porque: Se os passageiros estão optando por lotações, é porque estão sendo melhor atendidos por esse transporte. Não se preocupe. Se cair o telefone é porque estou no celular. [Causal] 4 já que, uma vez que: Se você sabe tudo, por que está perguntando? Se você não sabe Inglês, não adianta fazer a prova. [Integrante] $\mathbf{5}$ introduz oração que funciona como complemento da principal: Gostaria de saber se as visitadoras já chegaram. Em 1 e 2 constrói-se com Subj. (BORBA, 2011, p. 1261)

Como podemos observar, o verbete que, novamente, tem uma extensão maior do que o se. Há nove acepções, no primeiro, e cinco, no segundo. Do mesmo modo que o Bechara, os verbetes do Unesp especificam cada classificação das conjunções. Assim, na microestrutura de que, a primeira informação sobre a palavra definida é a sua classe gramatical, um componente do paradigma informacional. Embora a definição seja feita por meio de uma frase, não há menção à oração subordinada substantiva, mas às funções sintáticas do substantivo (sujeito e complemento nominal). O paradigma pragmático segue essa mesma orientação, apresentando um exemplo de uso em que a oração subordinada exerce a função de sujeito e outro com a de complemento. Como nos exemplos de Bechara, os exemplos nesse dicionário são simples e curtos, de linguagem mais comum. Ao final do verbete, vemos mais uma informação pragmática sobre o que, mas dessa vez sobre seus usos coloquiais. 
O verbete se segue a mesma lógica do que, apresentando a informação gramatical da palavra definida, uma definição cujo foco é a função gramatical e um exemplo de uso no qual se apresenta um período composto por subordinação. Há indicações pragmáticas, mas elas se referem às outras acepções do se, enquanto conjunção condicional. É interessante notar ainda que, diferentemente do Bechara, o Unesp trouxe a acepção referente à função integrante da conjunção por último. A estratégia aqui pode ser a de facilitar a consulta ao dicionário, entendendo que o sentido do se como partícula de condição seja o mais conhecido pelos alunos. Assim, parte-se de um conceito dado para estabelecer um novo.

Continuando com nossas análises, apresentamos os verbetes do Aulete:

que $^{2}$ conj. 1 Introduz oração com função de sujeito, complemento, predicativo de outra oração (p. ex.: em Pensei que hoje fosse chover, que fosse chover é o complemento de pensei) [a) No português corrente, substitui: 1) prep. de: Tenho que sair agora. 2) prep. a: Prefiro ouvir que falar. b) Por omissão de verbos como espero, desejo etc., inicia frases que expressam estímulo, invocação etc.: Que vença o melhor!] conj. comp. 2 Introduz o segundo termo da comparação, podendo ser precedido ou não da prep. de: Era mais alto (do) que qualquer outro de sua idade. conj. 3 Introduz oração que é consequência do que foi dito na oração principal: Estava tão atrasado, que esqueceu os documentos. conj. expl. 4 Porque; devido a: Não the ofereça carne, que ela é vegetariana. No Assim que; quando: No que ele saiu, começou a chover. (GIEGER, 2011, p. 1138)

$\mathbf{s e}^{2}$ conj. 1 Introduz uma oração que é complemento da oração principal: Não disse se chegaria cedo. conj. condic. 2 Na condição de; caso: Se você explicar o caminho, vou sozinha. conj. caus. 3 Já que, visto que: Se alguns têm dúvidas, é melhor adiarmos a prova. conj. temp. 4 Quando, enquanto: Se nada fala, todos reclamam. [F.: Do lat. si. Hom./Par.: sé (s.f).] (GEIGER, 2011, p. 1247)

O verbete que do Aulete é estruturado de modo parecido aos dos verbetes dos outros dicionários analisados. Há a identificação da classe gramatical, mas, diferentemente das outras obras, não há uma indicação específica à categoria conjunção integrante, como se todas as conjunções introduzissem orações com função de sujeito, complemento ou predicado. Ao não fazer essa distinção, o dicionário dá a entender que a conjunção comparativa e a explicativa são subcategorias das conjunções integrantes, o que pode confundir os consulentes.

Com relação ao paradigma definicional, vemos a definição ser construída a partir de explicação gramatical, com termos que remetem à 
v. 11 (esp.)

$64-80$ ago. 2021

sintaxe. É interessante destacar que, quanto ao paradigma pragmático, este é muito semelhante ao do Bechara, trazendo até os mesmos exemplos para mostrar as possíveis substituições feitas com o que.

Há ainda nesse verbete, como no de Bechara, uma subentrada que é definida com sinônimos, sem nenhuma explicação gramatical. Mas, no Aulete, há a presença de um exemplo de uso, o que facilita a compreensão da locução, já que o usuário pode vê-la sendo usada em um contexto.

Como nos outros dicionários, o verbete se é bem menos detalhado do que o de que. Observamos um paradigma definicional menos extenso e informações contextuais limitadas ao exemplo de uso. Sobre o paradigma informacional, há novamente a menção à classe gramatical sem especificação, como ocorreu com o que, e a origem etimológica da palavra, o que também é visto em Bechara.

Abaixo, podemos observar os verbetes do Houaiss:

que prono. rel. 1 Substitui um termo antecedente, nome ou pronome, assumindo suas funções <o rapaz q. passou é pedreiro > $<$ li um livro q. teve boa crítica> $\mathbf{2}$ confere à oração que inicia a função de adjetivo <a casa, q. acabaram de construir, ruiu> pron. ind. 3 us. Em frase interrogativa <q. significa esse traço? $>4$ us. Em frase exclamativa <q. espanto! $>$ conj. intg. 5 confere à oração subordinada as funções de substantivo, p. ex., a função de sujeito na frase é necessário que fique bem claro, ou de objeto direto em sabia que tinha de tomar vacina. conj. sub. adv.6 confere à oração subordinada valores circunstanciais $\mathbf{6 . 1}$ de causa < já q. as pernas tremiam, sentou-se> $\mathbf{6 . 2}$ de tempo <sempre q. liga a televisão adormece $>\mathbf{6 . 3}$ de fim < afastaram-se para q. outros não os vissem> $\mathbf{6 . 4}$ de proporção <à proporção q. os professores iam saindo, os alunos ficavam mais descontraídos> $\mathbf{6 . 5}$ de comparação <é teimoso q. nem o pai> $\mathbf{6 . 6}$ de consecução <tão exagerado q. muitos o chamam de louco > conj. coord. explc. 7 introduz explicação para o que antes foi dito <espere um pouco que a chuva já vai parar $>$ adv.8 quão <q. bela é a noite!> [ETIM: do lat. quid, do pro. interrogativo quis, quae, quid] (HOUAISS, 2011, p. 779)

${ }^{2}$ se conj. cond. $\mathbf{1}$ no caso de <se chover, não vou> conj. temp. $\mathbf{2}$ quando, enquanto <se fala, irrita a todos> conj. caus. $\mathbf{3}$ visto que, uma vez que <se você tem carro, por que ir a pé?> conj. intg. 4 se acaso, se por acaso, se porventura <não seu se ele vem> [ETIM: do lat. conj. si 'se'] (HOUAISS, 2011, p. 847)

Ao lermos o verbete que do Houaiss, notamos que o dicionário escolheu registrar, em um único verbete, as duas classificações gramaticais para essa palavra, optando pela polissemia e não pela homonímia5, como ocorreu com as outras obras aqui analisadas. Assim,

${ }^{5}$ A homonímia ocorre quando um dicionário compreende um conjunto de unidades léxicas diferentes sendo representadas por um mesmo significante. Já a polissemia é a interpretação de que um único vocábulo possui diferentes significados (PONTES, 2009). 
vemos que a quinta acepção marca mudança de classe gramatical da entrada de pronome para conjunção. O paradigma definicional parece seguir os mesmos parâmetros dos outros dicionários, construindo o significado da conjunção através de uma explicação gramatical. Entretanto, a escolha do termo confere no início da definição traz a ideia de que o que funciona como transpositor/nominalizador, como apontam Bechara (2017) e Bagno (2012). O paradigma pragmático, nesse sentido, apresenta um exemplo de uso junto a uma explicação do que seria essa transformação de uma oração em um sujeito e em um objeto direto. Faz parte ainda do paradigma informacional, a referência à origem etimológica da entrada.

Com relação ao verbete se, observamos que o dicionário não optou por manter o critério da polissemia como ocorreu em que, já que a entrada é classificada apenas como conjunção, ficando a função de pronome em outro verbete. No paradigma informacional, há a menção à classe gramatical específica em cada acepção e a origem etimológica da palavra. O paradigma definicional, desta vez, é constituído por sinônimos, diferente dos outros verbetes estudados. Mas os sinônimos que compõem a definição são locuções também formadas com o se, que não esclarecem totalmente seu significado. Além disso, a compreensão da conjunção parece estar atrelada ao conhecimento de acaso, porventura, palavras não usuais aos usuários dessa obra. Sobre o paradigma pragmático, entre colchetes, ele é constituído de um exemplo de uso, sem nenhuma explicação gramatical sobre as orações subordinadas.

Após a leitura de todos os verbetes, observamos que o conceito das conjunções integrantes que e se é construído tendo como base sua função sintática, como elemento de introdução de uma oração subordinada substantiva. Essa função é marcada nas informações que compõem os paradigmas do verbete, com termos que remetem à sintaxe. Constatamos, nesse sentido, que o dicionário assume o mesmo posicionamento que as gramáticas de orientação normativa. Notamos ainda a importância do paradigma pragmático para a compreensão do sentido das conjunções, pois os exemplos de uso ajudam a entender os contextos em que elas funcionam, e as orientações sobre o emprego dessas partículas podem guiar o aluno na produção de textos. 
v. 11 (esp.)

$64-80$ ago.

2021

\section{Considerações finais}

Esta pesquisa pretendeu descrever as informações lexicográficas presentes nos verbetes das conjunções integrantes que e se dos dicionários escolares tipo 4 presentes no PNLD-2012. Nossas análises mostraram que a conjunção integrante é definida, pelo dicionário, pela sua função enquanto elemento gramatical, não possuindo traços semânticos de significado próprio, embora um dicionário, o Houaiss, tenha definido o se através de sinônimos.

Sabendo da dificuldade dos usuários destes dicionários em relação a conceitos sintáticos, especialmente os referentes ao período composto, a opção dos lexicógrafos por esse viés pode não ser a mais eficiente, pois, para compreender o verbete, o aluno deve antes ter conhecimento sobre uma série de preceitos sintáticos. Além disso, o ensino baseado em nomenclaturas e classificações provou-se ser pouco produtivo para a leitura e a produção de textos.

Considerando, no entanto, a dificuldade de definir palavras que não possuem significado próprio, como as conjunções, é desafiador para o dicionário não se basear em conceitos da Gramática, disciplina que tem por tradição o estudo desses elementos. Mas a Gramática, como campo da Linguística, ao longo dos anos, desenvolveu teorias novas, baseadas na observação da língua em uso. Nesse contexto, podemos citar a gramática de orientação funcional, que defende a ideia de que não há sistemas autônomos da língua e que a gramática só pode ser estudada em conjunto com a semântica e a pragmática. É papel do dicionário escolar, nesse sentido, acompanhar essas mudanças e rever as bases gramaticais que sustentam as definições dos seus verbetes, visto se tratar de um material didático de auxílio ao aprendizado de uma língua.

\section{Referências}

ARAÚJO, Edna Maria Vasconcelos Martins. o dicionário para aprendizes em sala de aula: uma ferramenta de ensino e aprendizagem. 2005. $233 \mathrm{f}$. Dissertação (Mestrado em Linguística Aplicada) - Programa de Pós-graduação em Linguística Aplicada, Centro de Humanidades, Universidade Estadual do Ceará. Fortaleza, 2005.

BAGNO, Marcos. Gramática Pedagógica do português brasileiro. São Paulo: Parábola Editorial, 2012.

BECHARA, Evanildo. Moderna gramática portuguesa. 37 ed. Rio de Janeiro: Nova Fronteira, 2009. 
BECHARA, Evanildo. Dicionário da língua portuguesa Evanildo Bechara. Rio de Janeiro: Nova Fronteira, 2011.

BORBA, Francisco S. Dicionário Unesp do português contemporâneo. Curitiba: Piá, 2011.

BRASIL. Ministério da Educação. Secretaria de Educação Básica. Programa Nacional do Livro Didático - Dicionários. Com direito à palavra: dicionários em sala de aula. Brasília: Ministério da Educação, Secretaria de Educação Básica, 2012. Disponível em http://portal.mec.gov.br/index.php?option=com docman\&view=download\&alias $=12059$ - dicionario $-e m-$ sala - de - aula - pnld pdf\&Itemid=30192> Acesso em: 10.jul.2020.

CUNHA, Celso; CINTRA, Lindley. Nova gramática do português contemporâneo. 7. ed. Rio de Janeiro: Nova Fronteira, 2017.

GEIGER, Paulo (org.). Novíssimo Aulete dicionário contemporâneo da língua portuguesa. Rio de Janeiro: Lexikon, 2011.

GRAMA, Daniela Faria. Uma análise lexicográfica dos elementos coesivos sequenciais do português para a elaboração de uma proposta de definição: um estudo com base em corpus. 2016. 371 f. Dissertação (Mestrado em Estudos Linguísticos) - Programa de Pós-graduação em Estudos Linguísticos, Instituto de Letras e Linguística, Universidade Federal de Uberlândia. Uberlândia, 2016. Disponível em < https://repositorio.ufu.br/handle/123456789/18084> Acesso em: 10.jul.2020.

HOUAISS, Antônio (org.); VILLAR, Mauro de Salles (ed. resp.). Dicionário Houaiss conciso. São Paulo: Moderna, 2011.

NASCIMENTO, Francisco Iaci do. O uso do dicionário escolar de língua materna por alunos do $5^{\circ}$ ano de uma escola pública do município de Palhano-CE. 2013. 265 f. Dissertação (Mestrado em Linguística Aplicada) - Programa de Pós-Graduação em Linguística Aplicada, Centro de Humanidades, Universidade Estadual do Ceará. Fortaleza, 2013. Disponível em<http://www.uece.br/posla/ download/dissertacoes-por-turma-2011-a-2019/ Acesso em:10.jul.2020.

PONTES, Antônio Luciano. Dicionário para uso escolar: o que é e como se lê. Fortaleza: EdUECE, 2009.

SOUSA, Ana Grayce Freitas de. Com a palavra o consulente: as relações entre imagem e texto em verbetes ilustrados. 2014. 208 f. Dissertação (Mestrado em Linguística Aplicada) - Programa de Pós-Graduação em Linguística Aplicada, Universidade Estadual do Ceará, Fortaleza, 2014. Disponivel em <https:// repositorio.unesp.br/handle/11449/93971> Acesso em: 10.jul.2020.

SOUSA, Ana Grayce Freitas de; SANTOS, Hugo Leonardo Gomes dos. Vinte anos de PNLD - Dicionários: Impactos pedagógicos e acadêmicos. Série Educar - Volume 37 - Teoria Educacional / Organização: Editora Poisson Belo Horizonte-MG: Poisson, 2020. Disponível em < https://poisson.com.br/2018/ produto/serie-educar-volume-37-teoria-educacional/>Acesso em:10. jul.2020.

SPERANÇA, Ana Carolina. Incompletudes da abordagem tradicional e suas implicações no ensino/aprendizagem da língua: um recorte sobre as relações de coordenação e subordinação nos períodos compostos. 2007. 132 


\section{v. 11 (esp.)}

$64-80$

ago.

2021

f. Dissertação (Mestrado em Linguística e Língua Portuguesa) - Programa de Pós-graduação em Linguística e Língua Portuguesa, Faculdade de Ciências e Letras, Universidade Estadual Paulista Júlio de Mesquita Filho. Araraquara, 2007. Disponível em < https://repositorio.unesp.br/handle/11449/93971> Acesso em: 10.jul.2020. 